Daimon. Revista Internacional de Filosofía, no 83, 2021 pp. 7-22

ISSN: 1130-0507 (papel) y 1989-4651 (electrónico)

http://dx.doi.org/10.6018/daimon.337461

Las obras se publican en la edición electrónica de la revista bajo una licencia Creative Commons ReconocimientoNoComercial-SinObraDerivada 3.0 España (texto legal). Se pueden copiar, usar, difundir, transmitir y exponer públicamente, siempre que: i) se cite la autoría y la fuente original de su publicación (revista, editorial y URL de la obra); ii) no se usen para fines comerciales; iii) se mencione la existencia y especificaciones de esta licencia de uso.

\title{
Escribir en sueños. Zambrano, Derrida y la temporalidad de la novela
}

\author{
Writing in Dreams. \\ Zambrano, Derrida and the Temporality of the Novel
}

JUAN EVARISTO VALLS BOIX*

Resumen: El propósito del presente estudio consiste en pensar la ambivalencia con que Zambrano aborda el género de la novela. De un lado, las reflexiones en La confesión, género literario posicionan a Zambrano próxima a las críticas de Benjamin y Adorno a propósito de la cosificación de la novela como género burgués de consumo. De otro lado, sus exposiciones en El sueño creador conciben la novela como la actualización del sueño de la libertad mediante el que el hombre se piensa desbordando la medida de lo humano. Esta ambivalencia del género revela al relato como la condición de posibilidad e imposibilidad de una temporalidad incalculable, no cuantitativa, lo que vinculará las reflexiones de Zambrano con el pensamiento de Derrida.

Palabras clave: Zambrano, Derrida, novela, tiempo, sueño.

\begin{abstract}
The aim of this study is to think the ambivalence with which Zambrano tackles the novel's gender. On the one side, her thesis in $L a$ confesión, género literario bring Zambrano closer to Benjamin, and Adorno's critique to the novel as a bourgeois and consumable gender. On the other side, Zambrano's statements in El sueño creador depict the novel as the fulfillment of a dream of freedom, where man can question himself beyond the limits of the human. In this ambivalence, the narrative gender shows both the conditions of possibility and the conditions of impossibility of a non-quantitative temporality. This aporetic character of the novel opens a discussion between Zambrano and Derrida's thought.
\end{abstract}

Keywords: Zambrano, Derrida, Novel, Time, Dream.

Recibido: 16-07-2018. Aceptado: 31-10-2018.

* Profesor asociado en el Departamento de Filosofía de la Universidad de Barcelona. valls-boix.j.e@ub.edu. Líneas de investigación: filosofía de la literatura, deconstrucción, relaciones entre estética y política en la filosofía contemporánea. Publicaciones recientes: Valls Boix, Juan Evaristo (2020): "Confesar lo que no se sabe. Jacques Derrida y las políticas de la confesión”, Archivum, 70-1, pp. 283-314; Valls Boix, Juan Evaristo (2020): "De la gran huelga literaria. Jacques Derrida y los desvíos del performativo", Quaderns de Filologia. Estudis Literaris, no. 25, pp.187-205. 


\section{Antes de empezar}

Hay quienes escriben de día y quienes escriben de noche. Sin embargo, todos escribimos de un modo u otro en sueños. Kafka, Walser o Benjamin continuaron sus sueños a través de sus textos, y la lista se extiende hasta la escritura soñada de Cixous. Dos casos ejemplares son Robert L. Stevenson y Ludwig Wittgenstein. El primero confesaba en su "Ensayo sobre los sueños" (2013, 85-6) lo siguiente:

hay una cuestión que me preocupa sobremanera, porque yo $-[\ldots]-$ me siento tentado a veces a suponer que no soy ningún contador de historias, sino una criatura de a pie [...] toda la ficción que he publicado debería ser obra exclusivamente de un elfo, de algún familiar, de algún colaborador invisible al que mantengo encerrado en un desván oscuro mientras yo me llevo las alabanzas y él apenas un trozo del pastel [...] (traducción modificada).

Wittgenstein, por su parte, describió en su diario un sueño en que era elogiado por su hermana. Tras la escena, Dios le ordenaba arrodillarse ante la cruz, a lo que el austriaco respondía con la pereza de un recién levantado. El sueño-vivencia acaba cuando, por su desobediencia, es castigado con un chispazo de su lamparilla de noche y un golpe en el codo a modo de castigo, por lo que escribe:

Comprendí que Dios podía exigir de mí lo que quisiera, con la consecuencia de que mi vida se convertiría inmediatamente en un sinsentido si no obedecía. Pensé inmediatamente si no podría explicar todo como una ilusión y no como una orden de Dios; pero me resultaba claro que entonces tendría que explicar como ilusión toda religión en mí. Que tendría que negar el sentido de la vida (Wittgenstein, 2006, 28-30).

Si Stevenson se aprovechaba de las historias que soñaba para labrarse una carrera como escritor, Wittgenstein se encontraba en la situación de Abraham en Temor y temblor. Sin embargo, ambos comparten un hallazgo: el sueño es el espacio de una desposesión, de la invasión de una alteridad que desconcierta y fascina, y al tiempo la secreta semilla de la escritura. Al tiempo, desposesión e invención. Al tiempo, pero ¿en qué tiempo se escribe? ¿Puede el tiempo desposeído de un sueño ser apropiado? Y si el tiempo soñado no pertenece a nadie, puesto que es un tiempo sin conciencia, ¿quién posee el rastro que deja en forma de novela? Nuestro propósito es pensar estas cuestiones desde el pensamiento cruzado de María Zambrano y Jacques Derrida.

\section{La novela, género ambivalente}

Según explica Zambrano en La confesión, género literario, la novela es un género moderno, pues surge de una necesidad de expresarse $(1995,24)$ propia del sujeto moderno. Este carece de una verdad vital que justifique su ser, pues la Modernidad se caracteriza por ese desencantamiento del mundo que, observa Zambrano, se inaugura con la escisión entre verdad y vida del racionalismo cartesiano y la invención del sujeto como cogito: mientras 
que la verdad se vuelve abstracta y se desdiviniza, la vida queda abandonada, errática en el vano espacio de lo humano. Ahora que el mundo ya ha perdido su encanto y su fundamento divino, el hombre ya no es un héroe ni tiene gesta. Ha perdido un sentido escatológico que le señalaba su lugar determinado en un universo ordenado, y se encuentra sin casa ni reino:

Antes, antes de que el yo cartesiano la barriera, había algo llamado alma, que nos imaginamos ahora como este espacio interior, como este reino de cada uno, tesoro donde se guardan las ocultas e imprevisibles posibilidades de cada cual, su secreto reino. Este espacio fue borrado y en su lugar aparecieron los "hechos psíquicos" o los "actos de conciencia" (Zambrano, 1995, 102-3).

El hombre moderno es también un hombre desterrado. Solo cuenta con su historia y su camino errabundo de exilio. De esta forma, "queda, de un lado, el sujeto a solas, y del otro, la totalidad de la vida como algo a recorrer o a escalar imposiblemente" $(1998,76)$. El hombre moderno surge como figura a partir de una herida: ha sido arrancado de una matriz escatológica que concebía la verdad como una forma de vida, como una revelación vivida. Tiempo y verdad ya no son vivibles, sino apropiables; ya no son cuestión de una vida, sino de una epistemología.

Esta errancia y esta carencia de verdad se torna en necesidad del género de la novela, pero también del de la confesión. Por ello confesión y novela son géneros "coetáneos" $(1998,25)$, y por ello Wittgenstein y Stevenson tienen todavía mucho de hombre moderno: en la agonía del primero y en la frivolidad del segundo se testimonia todavía el dolor de una herida. No en vano señalaba Zambrano que "el libro de Cervantes" era, más que un libro, "una herida" $(1964,32)$.

¿Y cómo se padece esta herida? Quizá aquí radique la principal "ambigüedad" (1998, 107) a que alude Zambrano para pensar la novela como género y, con ella, el tiempo. Escribe:

La vida real, el hombre real y concreto, quedaba, o ensoberbecido por la ideología positivista, que es lo único que se derivó de la razón dispersa, o humillado. Soberbia y humillación son las dos notas de la desesperación del alma moderna; sus dos polos $(1995,21)$.

Sobre estos dos polos, soberbia y humillación, oscilarán las valoraciones de Zambrano sobre la novela. Se trata, así, de una ambivalencia que enfrenta dos momentos de su pensamiento. De un lado, en La confesión, género literario, la novela es desprestigiada por encarnar la soberbia del sujeto moderno y devenir en objeto de consumo, basándose en una cosificación del tiempo y una objetivación de la verdad como relato. El hombre ha perdido el relato que articula su vida, pero puede consumir nuevos mitos que desempeñen esa función. La novela sería la prueba de esta decadencia del sujeto moderno ensoberbecido, que diseña sus coordenadas existenciales a través de una industria de consumo tanto epistémica como material. Aquí, la novela se concibe como lo opuesto de la confesión. Mientras que la confesión es una escritura que realiza la verdad en su desplegarse, y que nace como una "protesta contra ese yo original" del racionalismo cartesiano (Zambrano, 1995, 92), la novela es el género que traiciona la existencia al volverla un problema abstracto. En la 
diferencia de estos dos gestos se concentra la crítica de Zambrano a la novela: es, a su vez, la distinción entre acción y arte: "El que hace la confesión no busca el tiempo del arte, sino algún otro tiempo igualmente real que el suyo" $(1995,27)$.

Y sin embargo, por otro lado, el diagnóstico zambraniano del género novelesco en El sueño creador (1998) y en España, sueño y verdad (1994), ambos de 1965, resulta muy favorable. La novela ya no se concibe como lo opuesto de la confesión, sino como otra forma de desestabilizar la soberanía del sujeto consciente. Si la novela capta la ambigüedad del sujeto moderno, se debe a que, siendo un género derivado de la nueva subjetividad como racionalidad autoconsciente, trata a su vez de desbordar los límites de esta conciencia. Ello por dos razones: en primer lugar, el tiempo de la novela no es un tiempo virtual, como el tiempo del arte, sino un tiempo real: "una verdadera novela nos mantiene siempre en este mundo" $(1994,18)$. La novela ya no es el género que brinda un relato que ordena el mundo, sino que en ella hay algo de acción: no se deja de vivir en la lectura y la escritura de una novela, el relato supone la posibilidad de un tiempo excesivo a cualquier cronología, un tiempo de vida. Si hay una verdad relevante en las novelas, no es de carácter cognitivo.

En segundo lugar, este tiempo tampoco es un tiempo lineal:

a la conciencia corresponde un tiempo humano que es el tiempo del pasado, presente y porvenir, la cinematográfica cinta que se desliza y que no podemos sobrepasar. Mientras en el mundo fabuloso, el hombre interviene en un tiempo, actúa en un tiempo que traspasa" $(1994,25-6)$.

La forma de este tiempo vivido no es la del tiempo consciente, sino antes bien el tiempo de los sueños, el extraño tiempo sin forma en que el ser humano se inventa a sí mismo: el protagonista de las novelas se revuelve ante la naturaleza humana impuesta por los filósofos, que le condena a ser un ser sin historia $(1994,23)$, tan solo sujeto de conocimiento, y se sueña otro en la novela. Tal es el caso paradigmático de don Quijote:

La situación de Don Quijote se hace inteligible desde el cartesiano mundo de la conciencia: “¿Qué soy yo?: una cosa que piensa”. Y ante esto la criatura llamada hombre no puede resignarse. Parte de su ser pensante va hacia la acción, y entonces se piensa a sí mismo, y sin darse cuenta se inventa a sí mismo, se sueña, y al soñarse se da un ser, ese por el que penaba. $(1994,28)$

¿Qué significa "inventarse a sí mismo”? ¿Qué implica que la novela sea el espacio en que, desbordando la conciencia, el hombre sueña para sí otro ser, se embarca en el sueño de la libertad? Es lo que marca la diferencia entre géneros como la épica o la tragedia y la novela: la novela es la prosa sin héroe, el relato sobre la falta de relatos, la narración de unos personajes insignificantes que viven y emprenden aventuras para darse el ser que, en origen, les falta ${ }^{1}$. "Lo que antes era mandato o fatalidad de los dioses", explica Zambrano,

1 Aunque, como se verá, la novela siempre corre el peligro de reinsertar el mito en el mundo y anular ese momento de invención del sujeto, como apunta Bundgård $(2001,49)$. 
"en el mundo de la conciencia es propia invención del individuo" (1994, 35). Ello implica que aquella categoría heroica de la edad del mito es, en tiempos quijotescos, "invento, desvarío, novelería. La novela es el género de la ambigüedad porque recoge la ambigüedad del hombre cuando se da a sí mismo" $(1998,106)$.

De esta forma, "el horizonte se ha estrechado al humanizarse y acciones antes heroicas han venido a ser ambiguas" $(1994,19)$. Por ello don Quijote es, a la vez, un individuo que vive sueños y quimeras y el antihéroe por excelencia, un viejo débil que lejos de saber qué hacer y cómo, improvisa, se equivoca, se contradice: la unidad de acción y la unidad de sentido propias del héroe mítico están aquí desencajadas, solo hay un sentido sin acción (el Alonso Quijano encamado) o una acción sin sentido (todo el vagar de don Quijote): en suma, solo hay un sueño de libertad, una invención de sí mismo, una tentativa constante que constituye, en su falta de relato, otra especie de verdad. Sentencia Zambrano:

la conciencia humana estrecha los límites de la existencia igualmente humana. Y en ella el héroe es un novelero, alguien que se atreve por enajenación a querer ser más de lo que le está concedido. Su caridad se confunde con la vanidad. Su esperanza se resuelve en el delirio. $(1994,28)$

De este modo, Zambrano rescata en sus textos de los años sesenta ese otro polo de la humillación, de la herida y la vulnerabilidad de la subjetividad moderna, al hallar en la novela la escritura del "sueño de ser al descubierto, de descubrirse enteramente" (1998, 110). Esta humillación que ocurre en la novela, y por la que el género supone una "fatal contrapartida del racionalismo europeo clásico" $(1998,107)$, hará de la novela un espacio de escritura capaz de desactivar las implicaciones de la subjetividad consciente como "naturaleza humana".

En suma, veinte años separan dos diagnósticos muy distintos del género de la novela en el pensamiento de Zambrano. Nuestro propósito consistirá en pensar estos dos gestos como uno solo, en su ambigüedad, como una paradoja que sustenta a la novela como espacio literario subversivo y, a su vez, la imposibilita, la disuelve como producto de consumo. Como si la novela ofreciera tanto las condiciones de posibilidad como de imposibilidad de un tiempo y una verdad otros. Es en este segundo momento cuando el pensamiento de Derrida coincide con las críticas de Zambrano, y nos permitirá pensar la vigencia de la novela como una escritura emancipadora.

\section{El soberbio ilustrado. Stevenson y los negocios oníricos}

Si la novela es fruto de la soberbia del sujeto moderno, es porque sus relatos vendrían a estructurar ese tiempo que ha perdido su estructura para siempre, resolviendo un problema existencial con una operación teórica. El lector de novelas trata de imponerle a la vida una verdad allende la vida, una verdad sin tiempo vivido. Como observa Llevadot, "lo que le falta a la novela es tiempo, tiempo para que la verdad nazca, para que algo pueda saberse de veras" (Llevadot 2010, 84). Zambrano concibe así la novela como ese género burgués que perpetúa la huida de la vida y la escisión entre verdad y vida que el racionalismo clásico inauguró con el sujeto consciente (Tarantino, 2001, 80). 
La crítica de Zambrano se asemeja a la de Adorno, quien también observa que la novela surge con el desencanto del mundo $(2003,42)$, y que por ello exige narración e historia en el momento en que ya no es posible narrar, pues se ha desintegrado "la identidad de la experiencia, la vida en sí continua y articulada" (43). Ello es lo que explica, ahora en términos de Benjamin $(2009,40)$, que nuestra época sea tan pobre en historias y tan rica en información. Tanto Adorno como Benjamin apuntan aquí a la misma valoración de Zambrano: la novela falsifica la realidad al presentarla como relatable. Como producto de consumo, produce en forma de ídolo lo que el hombre ya ha perdido. Con ello, del mismo modo que no habría en la novela más que una verdad positiva, tampoco habría otro tiempo que el tiempo calculable, es decir, un tiempo sucesivo y homogéneo. Por ello apunta Adorno que "la novela debería concentrarse en lo que la crónica no puede proveer" (2003, 43), esto es, en otra forma de tiempo, un tiempo sin la forma que impone el positivismo.

A su vez, explica Zambrano tiene su origen "en la linterna mágica" y crea un "tiempo mitológico" $(1995,26)$ que es "otro tiempo que el de la vida", un tiempo en que uno se pierde sin "encararse a la realidad", y cuyo transcurrir "termina en algo efectivo y canjeable" (28). El sujeto moderno está desahuciado, y busca reemplazar la casa que perdió adquiriendo una propiedad: su tiempo y su verdad son producto de su racionalidad, y se reducen, separados de la vida, a mitos y fetiches. El sujeto moderno se olvida de su herida con la comodidad y la diversión de esos "buenos libros" que son las novelas. Inaugura el tiempo como sucesión mensurable de entidades equivalentes, y permite con ello un pensamiento económico que, en su relatar una vida que ya carece de unidad, supone una reinserción del mito en la racionalidad ilustrada y una vuelta a una casa ontológica allí donde solo queda la intemperie.

De esta forma, la novela perpetúa el olvido de la vida que inaugura la filosofía moderna. El tiempo en que se estructura es un tiempo positivo que, al ser transcrito, se estructura como tiempo abstracto, mientras que el tiempo de la vida "no puede ser transcrito, es el tiempo que no puede ser expresado ni apresado" $(1995,28)$. La novela implica así una "objetivación artística", "una de las más graves acciones que hoy se pueden cometer en la vida", un "puro narcisismo" (29-30). El sujeto queda encerrado en un "círculo mágico" (66) de pura actividad. Hay, en el tiempo de la novela, como tiempo abstracto que violenta y estructura la vida más allá de la vida, actividad, pero no acción ni transformación (Pérez Navarro, 2001, 55). El tiempo de la novela se describe a través de una semántica económica que lo encierra en la figura circular pasado-presente-futuro y, lo torna en algo apropiable.

Es en este punto en que Zambrano coincide con las reflexiones sobre el tiempo de Derrida en Donner le temps (1991b). Derrida, como Zambrano, observa que el tiempo excede cualquier esquema económico y no se deja poseer:

Si un temps appartient, c'est que, par métonymie, le mot temps désigne moins le temps lui-même que les choses dont on le remplit, dont on remplit la forme du temps, le temps comme forme [...] Apparemment et selon la logique ou l'économie courante, on ne peut qu'échanger, par métonymie, prendre ou donner ce qui est dans le temps. (Derrida, 1991b, 14) 
Del mismo modo, Zambrano observa que "estamos siempre suspendidos del uso del tiempo, de que estamos en él, inmersos, mas sin poderlo usar; de que asistimos propiamente a un tiempo sin dueño". $(1998,17)$ Así, tanto Derrida como Zambrano señalan que la formatiempo de la metafísica, en tanto que guarda la forma del círculo e implica una cuantificación de la experiencia, es lo más ajeno al tiempo como tal, al tiempo de la vida. Como si la contabilidad del tiempo imposibilitara cualquier donación genuina de tiempo, cualquier posibilidad de un tiempo que vivir. Escribe Derrida, así, que "la temporalisation du temps (mémoire, présent, anticipation ; rétention, protention, imminence du futur ; extases, etc.) engage toujours le processus d'une destruction du don" (1991b, 27). Esta temporalización del tiempo es la base para una comprensión del hombre como una conciencia que aprehende fenómenos como inmediatamente presentes a ella. Y este privilegio del presente o de la presencia implica una comprensión concreta del ser: "la métaphysique n’aurait interprété l'être (Sein) comme étant-présent qu'à partir d'une préinterprétation du temps, précisément, pré-interprétation qui accorde un privilège absolu au maintenant-présent ". (1991b, 32-33)

En este sentido, Zambrano observaba igualmente que, si hay una verdad de la vida, esta jamás puede sernos presente: "La verdad mora en el interior del hombre no en imagen, no en reflejo, sino en realidad, aunque tan inmensa realidad no pueda ser ni vista ni imaginada, ni puede sernos presente". $(1995,64)$ La verdad de la vida resulta excesiva a la economía del tiempo como presencia.

Por último, ambos coinciden al concebir el círculo económico del tiempo y la ordenación del relato como una figura del retorno a la casa y la repatriación. La estructura del relato, dirá Derrida, es "odiseica". "L'oikonomia", prosigue,

emprunterait toujours le chemin d'Ulysse. Celui-ci fait retour auprès de soi ou des siens, il ne s'éloigne qu'en vue de se rapatrier, pour revenir au foyer à partir duquel le départ est donné et la part assignée, et le parti pris, le lot échu, le destin commandé (moira). L'être-auprès-de-soi de l'Idée dans le Savoir Absolu serait odysséique (1991b, 21).

Con ello, la novela imposibilita cualquier donación de tiempo vivido, hace creer al burgués que está en la casa de su interioridad y no en un errar constitutivo. El relato, en tanto que implica esta temporalidad, liquida al tiempo como donación (Derrida, 1991b, 195): "partout où il y a du temps, partout où le temps domine ou conditionne l'expérience en général, partout où domine le temps comme cercle (concept 'vulgaire', dirait donc Heidegger), le don est impossible" (21).

Las palabras de Stevenson son ahora más claras, quizá también más complejas. Él mismo presumía de poder saldar sus deudas vendiendo varias historias escritas a partir de algunas ideas reveladas en sueños $(2013,79-80)$, como si reinsertara en la circulación económica aquello que la excedía. Y a este respecto, especifica algo más. Repetimos la cita del inicio sin la omisión:

hay una cuestión que me preocupa sobremanera, porque yo - lo que yo llamo yo, mi ego consciente, el morador de la glándula pineal a menos que haya cambiado de residencia después de Descartes, y el hombre con la conciencia y la cuenta corriente oscilantes, el hombre que lleva botas y sombrero, que goza del privilegio del voto y 
que no lleva a su candidato a las elecciones generales - me siento tentado a veces a suponer que no soy ningún contador de historias, sino [...] un realista metido en el día a día hasta las orejas $(2013,85)$

Stevenson, como ego consciente, se dedicaba a gestionar sus historias soñadas para que dieran "rendimiento económico" $(2013,79)$, a reinsertar en la circulación del relato lo que la excede. Será el otro, ese colaborador invisible, el escritor genuino, quien ofrecerá las ideas singulares que Stevenson "vestirá" (80) en forma de novela.

Y hay sin embargo en estas páginas vanidosas una nota disonante que exige de nuevo una pregunta por la ambigüedad de la novela, que es la ambigüedad del tiempo y su verdad. Stevenson relata su capacidad para soñar sus cuentos como una confesión: habla de un soñador anónimo que reconoce, al final, como él mismo: "Respecto al soñador, puedo decirles que soy yo mismo, ni más ni menos" $(2013,85)$. Lo hace en el momento en que explica cómo concibió lo que quizá es su obra maestra, Jekyll y Hyde, ese relato en que Jekyll, a través de Hyde, sigue reclamando la donación sin economía del tiempo, y que, siendo inicialmente una novela detectivesca, acaba igualmente con un testamento, con una larga confesión en que la conciencia diurna se torna un anhelo de libertad nocturna.

\section{El humillado sin tierra. Wittgenstein y el tiempo de los sueños}

Es justamente esta hipótesis la que, a diferencia de Llevadot o Bundgård, sostienen otros investigadores como López Sáenz (2011) o Maillard García (1996). Apunta esta última que

No desestima por tanto Zambrano la narración - o la configuración de la tramacomo esclarecimiento de la vida, sino todo lo contrario. A partir de la modernidad es en el género de la novela donde se va a refugiar esa forma de conocimiento capaz de transformar el tiempo sucesivo en un tiempo uno que muestre la vocación de ese "más" que se esconde tras la libertad y desde ella llama a la vida. (57)

Y es que, pese a sus críticas, Zambrano reconoce que "todo arte tiene algo de confesión desviada" (1995, 28), y que "cuando la novela ha llegado a ser tiempo de la vida -Proust, Joyce - es que se trata en realidad de una confesión" (28). Ello implica que, si el tiempo sucesivo es tan solo "una de las modalidades del tiempo" $(1998,117)$, y hay una "multiplicidad de los tiempos vitales" $(1998,28)$, la novela, en tanto que una forma de transcripción del tiempo, puede albergar un tiempo otro. Un tiempo que, a diferencia del sucesivo, dé lugar a "la integración de la persona" y a su "renacer" $(1998,131)$, un tiempo que sea un "punto de contacto entre la vida y la verdad", y que, además de relatar, permita esa "operación de la vida misma" a través de la que la vida se "transforma" (132). Como si la transcripción del tiempo imposibilitara el tiempo de la vida por apresarlo, pero a su vez supusiera la posibilidad de un tiempo transformador, un tiempo que viniera a interrumpir el fluir del tiempo de la conciencia y, al quebrantarlo, pusiera en cuestión las limitaciones del cogito: como si en las palabras del relato se pudiera realizar una acción, más allá de cualquier actividad.

La vivencia-sueño de Wittgenstein es un ejemplo de ello. Su despertar, confundido con un sueño, se cifraba en una suerte de instante sin tiempo en que, inmóvil, sintió su 
vulnerabilidad ante Dios como la revelación de una verdad definitiva que, aun incapaz de probarse, no podía en ningún caso ser tomada como ilusión. Ese otro tiempo de la acción transformadora a que aludía Zambrano, y que subyace a la vivencia-sueño de Wittgenstein, es en el pensamiento de Derrida el tiempo del don, el tiempo de un acontecimiento que rasga la continuidad de la temporalización y desestabiliza su economía: un tiempo incontable, un instante paradójico que nunca es presente, y que solo puede comprenderse fuera de la organización del tiempo desde el presente. Escribe Derrida: "Pour qu'il y ait événement (nous ne disons pas acte) de don, il faut que quelque chose arrive, en un instant, un instant qui sans doute n'appartient pas à l'économie du temps, dans un temps sans temps" (1991b, 30), a lo que añade: "Un don ne saurait être possible, il ne peut y avoir don qu'à l'instant où une effraction aura eu lieu dans le cercle" (21).

Así, tanto Zambrano como Derrida consideran que, en el relato, hay un tiempo propio de la sucesión y del encadenamiento, y otro tiempo, un tiempo sin tiempo que consiste en un instante de interrupción inenarrable que, al dar lugar al acontecimiento y a la acción transformadora, exige, pese a imposibilitarlo, que el relato vuelva a comenzar, que comience de nuevo la historia y se cuente aquello que ha ocurrido en un tiempo incontable. "Quant à l'économie du récit et au récit de l'économie", explica Derrida, "le don, s'il y en a, requiert à la fois et exclut la possibilité du récit. Le don est à la condition du récit, mais simultanément à la condition de possibilité et d'impossibilité du récit" (133), es decir "ils doivent déchirer la trame, interrompre le continuum d'un récit que pourtant ils appellent" (156). El don del instante inicia e interrumpe la sucesión del tiempo, el tiempo como relato. Así, Derrida ofrece un desarrollo explícito de una problemática que Zambrano ya entreveía, pero solo señalaba a propósito de la ambivalencia de la novela, que siendo el género eminentemente humano, asume la pluralidad del tiempo y las verdades que en él se inscriben: abre la problemática de un texto que se encuentra en un espacio indecidible entre un constativo (relatar) y un performativo (actuar). En el gesto de Zambrano se puede leer, en cierta forma, la afirmación de Derrida de que la problemática del don, y por ende del tiempo, ha de reenviar siempre a una problemática del trazo y del texto $(1991 b, 131)$. En suma, "le récit donne et tue le temps" (195), y esta paradoja, que revuelve el orden de la conciencia, estará en la base de esa otra especie de verdad a que Zambrano aludía en "Los orígenes de la novela" (2012).

Este tiempo sin temporalidad es, tanto en Derrida como en Zambrano, el tiempo de los sueños. Son los sueños lo que hacen de la filosofía de Wittgenstein una filosofía-confesión, y de las historias de Stevenson, novelas-confesión. Es el sueño el lugar en que el sujeto moderno es humillado y desposeído de su de su soberanía, donde se desborda la vigilancia de la conciencia y la temporalidad cotidiana se revela como una ilusión de homogeneidad. Como observa Zambrano, los sueños se caracterizan por privarnos del tiempo $(1998,17)$. En ellos la conciencia "no entra", tan solo "asiste" a lo que nos sucede $(1998,18)$, y por ello estamos también desposeídos de actividad. Los sueños nos someten a una atemporalidad y a una inmovilización. Sin embargo, del mismo modo que Derrida observaba que el don era condición de posibilidad e imposibilidad del tiempo del relato, Zambrano observa cómo el sueño es igualmente una condición incondicionada del tiempo y del espacio como formas de la conciencia. "El paso, pues", subraya Zambrano, "del sueño a la vigilia se da en el instante de vacío en el que comienza a fluir el tiempo. La vigilia es un fluir. El sueño, 
algo compacto, cerrado, en el que se representa algo concebido de antemano, de intención desconocida, de autor desconocido" (1998, 20-21).

Igualmente, la inmovilidad de los sueños, su carácter puro, "sin tiempo y sin espacio" $(1998,19)$, es la condición del movimiento. Si Derrida valora el don como la condición de posibilidad e imposibilidad del relato, o sea, el instante como condición de posibilidad e imposibilidad del tiempo sucesivo, Zambrano señalará de forma similar que los sueños son "la oscura raíz" de la sustancia de la persona $(1998,65)$. Con ello, los sueños son un espacio que revela la insuficiencia del horizonte humano para pensar al hombre, un conflicto de lo humano con la medida de lo humano, como la insuficiencia de la temporalidad para pensar el tiempo. Y es en la novela, en fin, como trasunto del sueño, donde se despliega este conflicto de la pluralidad del tiempo y la alteridad de lo humano:

La novela, género moderno por excelencia [...], muestra mejor que ningún otro producto de nuestra cultura ese conflicto entre conciencia, razón y piedad, servidumbre a lo divino, conflicto en el que va nuestra condición humana, nuestra definición. ¿Podemos definirnos, como es el más obstinado intento moderno, solamente en relación con "lo humano"? $(1994,19)$

A través de los sueños el hombre se excede a sí mismo como forma antropológica, se abre a una transcendencia sin forma ni medida. Como señala Derrida, "s'il y a du don, il doit se donner comme un rêve, comme en rêve. Pour l'inconscient ou pour la conscience pure, il n'y a pas de don, ni de pardon, seulement de l'échange et de l'économie restreinte » $(1994,73)$. A través de los sueños, Zambrano - como Derrida - está practicando una “epojé del tiempo sucesivo. Se trata, en suma, de intentar una fenomenología del sujeto privado de tiempo, es decir, de sí mismo, ya que el medio del sujeto humano es la temporalidad" (Castilla, 2011, 12; cf. López Sáenz, 2007, 63ss).

Así, el tiempo se inaugura a partir de la atemporalidad del sueño a la vez que se interrumpe. El sueño revela el tiempo de la conciencia como una homogeneidad que hace a la realidad "indiferente por estabilizada" $(1998,22)$, cuestiona en su inmovilidad la economía del tiempo. Zambrano opera una inversión según la que en la realidad estamos dormidos, anestesiados en la estabilidad del fluir temporal, y solo en sueños despertamos, es decir, vemos alterada esa homogeneidad por una experiencia inasimilable, heterogénea a la conciencia. La vigilia se vuelve ilusión y el sueño deviene la más alta forma de despertar:

Sumergido el sueño, como decíamos, en la continuidad de la perfecta vigilia, llevada a cabo por la conciencia, encerrado dentro de la continuidad del presente, al que el tiempo sucesivo ha quedado reducido, envuelto por el medio así acotado dentro de la ilimitada "realidad", el hombre, reducido a sujeto consciente, quedaría como en un sueño. Sumergido en la pasividad bajo su continua actividad. (1998, 45-6)

En el mismo sentido, Wittgenstein confería a su vivencia-sueño el carácter de una realidad más efectiva y despierta que la del mundo cotidiano, que no deja de calificar de ilusión en una carta a Engelmann:

Nuestra vida es como un sueño. Pero en las mejores horas nos despertamos tanto que reconocemos que soñamos. No obstante la mayoría de las veces permanecemos en sueño profundo. No me puedo despertar a mí mismo. Me esfuerzo, mi cuerpo soñado hace movimientos, pero el real no se mueve. (Wittgenstein y Engelmann, 2009, 39). 
Zambrano está señalando con ello dos cuestiones: de un lado, en esta fenomenología sin temporalidad ni sujeto, tiene lugar el despertar a una realidad que, por estar desprendida de los límites de aquellos, es más efectiva y más próxima a la vida. De otro lado, este espacio onírico de atemporalidad revela al ser humano la pasividad como su situación inicial (1998, 56). En los sueños el hombre está inmóvil y tan solo padece, y esta pasividad es inconmensurable al entendimiento, pero intrínseca a la vida $(1995,18)$, que no está sino "cuando nos hemos colocado en situación de recibirla" (42). A través de los sueños, el hombre se desvincula de las coordenadas de la actividad y se instala en esta pasividad en la que se deja atravesar por aquello que viene en sueños y que no controla. Por ello, lo que padece el hombre es su propia transcendencia, lo que le excede y le vulnera. Y, a su vez, la pasividad de los sueños es, curiosamente, la más transformadora de las acciones, la que anuncia y hace venir una alteridad. En los sueños, esta trascendencia se manifiesta como otros modos de ser, otro modo que ser, más allá de la forma hombre.

Y es en este punto cuando Zambrano vincula sus reflexiones sobre los sueños con la palabra y con la novela. El despertar que genera el sueño en tanto acción de apertura a la transcendencia le valía a este el calificativo de "creador". Y pese a que ello se encuentre muy lejos de un tiempo que pueda ser transcrito, Zambrano observa que "este trascender que de los sueños reales se desprende encuentra, para cumplirse, el camino de la creación por la palabra" $(1998,75)$, una palabra que no es "lógica", sino una "acción trascendente del sujeto" (73). Son unas palabras que, en lugar de ofrecer un sentido definido, guardan esa oscura trascendencia que el sujeto padece en sueños; esto es, guardan su capacidad de interrumpir y despertar, y cuestionan el significado normalizado de la realidad. A ello parece aludir Zambrano cuando habla de contar un sueño: "se trataría, pues, tomando las cosas elementalmente, no de analizar, sino de contar simplemente un sueño" $(1998,78)$, lo que implica relatarlo "conservando su secreto sentido ya en la claridad" (77): preservar lo incomprensible como lo más lúcido, abrazar la indecisión del alba.

Al contar un sueño sin explicarlo, se manifiesta en las palabras su falta de sentido, se relata como aquello que viene sin cuento y sin estructura narrable. Y es en esta realización poética del sueño, y de su tiempo intempestivo, como un relato de la falta de relatos, donde Zambrano establece el vínculo entre sueño y novela y, por ende, entre tiempo de vida y relato: "Toda novela pone en marcha un sueño inmóvil" $(1998,116)$. Este sueño es el sueño de la libertad, de conquistar plenamente el ser, y es un sueño que solo puede escribirse como tal habida cuenta del desencantamiento del mundo y la trascendencia radicalmente incógnita del hombre. De no ser por ello, no se trataría de novelas, sino de tragedias u otros géneros. En el momento en que el hombre ha perdido una verdad fundamental de la vida, se sitúa ante ella desde el desconocimiento, y ya no tiene más ser que el que anhela y sueña. La novela es siempre tentativa e improvisación de una invención de sí, esto es, ensayo de una libertad, andadura para realizar el sueño de una libertad que siempre está limitada, que nunca permite al hombre dominar y conocer del todo su ser: una libertad como trascendencia, como padecer. Por ello mismo, las historias de los dioses no son novelas: ellos "o bien carecen por completo de libertad o la tienen tan entera y acabada, que se les confunde con su ser mismo" (1998, 114). La novela trae consigo la libertad, el sueño de la libertad, antes que el ser, y ello implica que la novela está constitutivamente en falta de estructura narrativa 
organizativa. Como los sueños, guarda inscrito, paradójicamente, el tiempo heterogéneo de la interrupción, del acontecimiento, de aquello que adviene a los personajes sin previsión.

\section{Escribir en sueños}

En docile je ne dis mot le rêve dicte j'obéis les yeux fermés. Hélène Cixous, Rêve je te dis

Así, la novela está ligada al sueño en tres aspectos: como acción transformadora, despierta a quien la escribe/lee y lo abre a su transcendencia, a una forma otra que ser en que el tiempo, el movimiento y la conciencia se encuentran suspendidos, excedidos. Como tiempo, es la temporalidad sin forma y sin relato, el tiempo de la tentativa, del anhelo de ser, del sueño de la libertad: nace, como tiempo, de un instante de efracción, de una pérdida de sentido o una ruptura del tejido de la realidad cotidiana que deja a sus protagonistas humillados y a la merced de lo que está por venir. Su verdad es la verdad sin relato, esto es, sin nada que desvelar, una verdad incognoscible que solo se muestra como llamada, como un aliento a la búsqueda y la escritura. El sueño se torna creador a través de la palabra, pero de una palabra que es performativa, y, por ende, rechaza el tiempo como presencia. De ahí que Zambrano hable de la novela como un anhelo del ser, y del sueño como una oración.

Continúa Derrida siguiendo los diagnósticos de Zambrano cuando, en sus escritos sobre Hélène Cixous, aborda el sueño como una invocación de la escritura:

Le rêve réveille. Le rêve veille et il veille à adresser des injonctions inflexibles à la veille, à la conscience vigilante encore en mémoire du rêve - une mémoire inouïe, dont je ne connais pas d'autre exemple. Le rêve assigne alors l'ordre d'écrire, de noter, voire de commencer à l'analyser, lui, le rêve. $(2003,50-2)$

La escritura de los sueños pone en obra una palabra que guarda la fuerza y la iniciativa del secreto. A este secreto alude Zambrano de diversas formas cuando explica que "lo que se entiende por realidad en sentido paradigmático es el sentirla venir de un último fondo. [...] Y esto último acentúa su carácter de sueño en un sentido que revela el fondo último de las cosas: su enigma" (1998, 22). También describe la verdad en sueños como un "lugar último", el trasfondo del que salen "jeroglíficos del destino" $(1998,39)$. Y pese a ser enigmática y jeroglífica, no es un "objeto de descubrimiento", sino que nos invoca "con alguna palabra suelta, sin significación alguna" $(1998,40)$, de forma que no puede ser analizada, esto es, "sometida a la conciencia despierta", sino solo descifrada, podemos tan solo "acompañarla desde el sombrío lugar, desde el infierno atemporal donde yace" $(1998,77)$.

Zambrano reflexiona sobre esta escritura del secreto en “¿Por qué se escribe?”, donde indica que el escritor siempre

quiere decir el secreto; lo que no puede decirse con la voz por ser demasiado verdad; las grandes verdades no suelen decirse hablando. [...] 'Hay cosas que no pueden decirse', y es cierto. Pero esto que no puede decirse, es lo que se tiene que escribir $(2000,34)$. 
De este modo, se escribe un secreto que se manifiesta en su irrevelabilidad, que se inscribe y se codifica en el lenguaje sin que por ello sea conocido, transcrito o apresado: "el secreto revelado no deja de serlo para quien lo comunica escribiéndolo. El secreto se muestra al escritor, pero no se le hace explicable" (35). Este secreto, que vincula en su condición insondable tiempo y verdad, y que se escribe como lo inexplicable, como lo indescifrable que guarda la singularidad, en su transcripción, de lo intranscribible - siguiendo al unísono los términos de Zambrano y Derrida-, desarticula, como ya lo hacían los sueños, la soberanía de la voluntad del sujeto y su estatuto de fundamento del pensar, y lo vulnerabiliza al confrontarlo a una zona oscura, a una luz que hace patente la oscuridad que nos envuelve.

En este sentido, el secreto de la escritura abre a quien escribe/lee a una alteridad que le trasciende. La escritura se despliega en la búsqueda de aquello oscuro que le llama, revela el ser en falta del sujeto, su verdad como secreto. No hay género más agudo para esta condición, no hay género más humano, por invocar este horizonte divino y trascendente, que la novela. Con ello, Zambrano concibe la escritura como un acto de fe (2000, 35), y esta fe se realiza en la novela como una aventura por un espacio ilegible, como una pasión por el secreto. Estas verdad y tiempo como secreto, efectivamente, quiebran los círculos de la economía del significado y de la conciencia, de la apropiación, de la restitución. Dan lugar a lo incalculable, a la posibilidad misma de lo imposible.

Así como Zambrano, Derrida sitúa en la literatura "le lieu absolu du secret même de cette hétéronomie, du secret comme expérience de la loi venue de l'autre" $(2003,59)^{2}$. Y ello por, al menos, las mismas razones que Zambrano. Observa en Donner le temps que

Un tel secret n'entre en littérature, il n'est constitué par la possibilité de l'institution littéraire, il n'est révélé par elle aussi dans sa possibilité de secret, que dans la mesure où il perd toute intériorité et toute épaisseur, toute profondeur. [...] Cette structure [...] est superficielle, sans substance, infiniment privée parce que publique de part en part. (1991b, 215-6)

De ahí el interés de Derrida por relatos como La fausse monnaie de Baudelaire o The Purloined letter de Poe: en ambos la escritura revela un espacio de indecidibilidad entre decir y no decir, entre manifestar y guardar. Como si, de la misma forma que don y economía, instante y temporalidad, sueño y relato, se implicaban y excluyen a la vez, siendo el uno la condición de posibilidad e imposibilidad del otro, la ilegilibilidad del secreto permite e impide la legibilidad del texto: la escritura asedia la palabra; el alba, en su oscuridad, es más lúcida, por tenebrosa, que la luz: "la lisibilité du texte est structurée par l'illisibilité du secret, c'està-dire l'inaccessibilité d'un certain sens intentionnel ou d'un vouloir-dire dans la conscience des personnages et a fortiori dans celle de l'auteur qui reste" (1991b, 191). De esta forma, tanto Zambrano como Derrida observan que la literatura, y la novela como relato de la falta de relatos, desdibujan las fronteras realidad/ficción, sueño/vigilia, memoria/invención, acción/ pasión y las devuelven a un mismo fondo de escritura y secreto. Para Derrida, pues,

2 Para un análisis en detalle del concepto de "secreto" en el pensamiento de Derrida, muy relevante en su producción de los años 1990 y 2000, remitimos a los análisis de Lisse (1999), a los estudios ya clásicos de Michaud (2006) y al reciente libro de Barbour (2017), en particular a su segundo capítulo. 
cette puissance propre à la littérature consiste à vous donner (c'est un don, génial et généreux), à vous donner à lire tout en vous privant [...] [de] le droit de décider, de trancher, entre réalité et fiction, témoignage et invention, effectivité et fantasme, fantasme de l'événement et événement du fantasme, etc. $(2003,59)$.

En esta línea asiente Zambrano, pues lo leído en una "verdadera novela", "puede confundirse en nuestra memoria con personajes y escenas que hemos realmente visto y vivido". $(1994,18)$

En suma, en Derrida y Zambrano tanto la literatura como el sueño trastornan el orden simbólico de la conciencia y el carácter homogéneo de la realidad. Con ello, están apuntando a una forma más vigilante de observar la realidad, que ambos conciben como un mantenerse despierto, una veille $e^{3}$. Con tono zambraniano, Derrida observa que

écrire au réveil, cela sous-entend encore autre chose. Hymne à l'adresse du réveil, peut-être, mais surtout, ce qui est tout autre chose, et un tout autre réveil, l'écriture au réveil marque une rupture absolument hétérogène. On peut, si l'on veut, appeler cela conscience littéraire. Mais c'est une conscience plus que consciente et dont l'hétérogénéité est aussi en situation d'obéissance hétéronome au regard de la Toutepuissance-autre de la littérature. [...] Ce réveil dans le réveil est donc l'extrême vigilance de la conscience littéraire la plus raffinée et la plus exercée, la plus audacieuse (2003, 54-57).

Esta conciencia literaria más vigilante, por onírica, que la conciencia diurna se estructura desde la fe y vela por hacer venir una alteridad, una trascendencia otra. Heteronomiza al sujeto, lo sumerge en sueños y lo priva de soberanía (Derrida, 2003, 58): lo devuelve a esa herida o secreto en que consiste su verdad, su tiempo y su escritura, e inaugura otra forma de "pensar el pensamiento" $(2002,21)$ que le exige decir sí al secreto y sí a los sueños (12-13), sí a la alteridad por venir y a un más allá del horizonte humano. En el alba y en el tiempo sin tiempo de los sueños y la novela el hombre, saliendo de lo humano, se aproxima a otra forma de vida, aborda la verdad de la vida como un vivir sin verdad.

\section{Nota conclusiva}

En definitiva, las dos aproximaciones de Zambrano al género de la novela, distanciadas unos veinte años entre sí, lejos de oponerse o reflejar una evolución en su pensamiento, se complementan y muestran una tensión que Derrida valoró como la problemática del don y el trazo. Así, Stevenson y Wittgenstein, el sujeto ensoberbecido que traduce el sueño en relato para comercializarlo, y el sujeto vulnerable humillado por una alteridad soñada, resultan dos efectos de la misma dinámica de escritura en la que una instancia incalculable (el sueño, el instante, el secreto, la alteridad, el don) es condición de posibilidad y de imposibilidad de un

3 Limitaciones de espacio nos impiden exponer la semejanza entre la estrategia zambraniana y la derridiana a propósito del despertar, el alba y la vigilia. Baste con aludir, a propósito de Derrida, a su texto "La veilleuse" (2001), y también a los estudios de Kamuf (2011) y Michaud (2010, en especial pp. 23ss). 
orden estabilizado (la conciencia, la temporalidad, la verdad como relato, la homogeneidad, la economía). Con ello, la novela es, de una parte, relato de sentido, vindicación del tiempo calculable, objetivación y narcisismo del sujeto, y por ello ideología, huida de la realidad, cancelación de la trascendencia, existencia a espaldas de la vida, soberbia del sujeto y su soberanía. De otro lado, la novela, nacida del desencanto y la pérdida del mito como metarrelato fundador, es un relato sin relato, la historia de la falta de historias, y por ello en su lectura y escritura hay acción transformadora, despertar al alba, actualización del sueño de la libertad, transcendencia como anhelo de ser y ansia de un horizonte otro que el humano, es decir, verdad vital como fundamento en falta y secreto, potencia de heteronomía, por venir.

La novela, género ambivalente y forma por excelencia de la escritura en sueños, se instala en este temblor y se encuentra siempre al borde de su cosificación y consumo, y al borde de ofrecer un despertar y una visión más aguda de la realidad para desnaturalizar los relatos que la consolidan. Entre esta exigencia y aquel peligro se mueve la novela, entre arte y acción, conciencia y vida, palabra y escritura. Anclada en la imposibilidad de distinguir entre sueño y vigilia.

\section{Bibliografía}

Adorno, Th. W. (2003), "La posición del narrador en la novela contemporánea”, en Notas sobre literatura, Madrid: Akal.

Barbour, Charles Oath (2017), Derrida's Secrets. Perjury, Testimony, Oath, Edinburgo: Edinburgh University Press.

Benjamin, Walter (2009), "El narrador. Consideraciones sobre la obra de Nikolái Léskov", en Obras completas, libro II/vol. 2, Madrid: Abada Editores.

Bundgård, Ana (2001), "Los géneros literarios y la 'escritura del centro' como transgénero en la obra de María Zambrano", Aurora, no. 3, pp. 43-51.

Castilla Cerezo, Antonio (2011), "Padecer y trascender: La crítica de Zambrano al análisis heideggeriano del concepto de tiempo", Aurora, no. 12, pp. 18-24.

Derrida, Jacques (2003), Genèses, généalogies, genres et le génie. Les secrets de l'archive, París : Galilée

Derrida, Jacques (2002), Fichus. Discours de Francfort, París: Galilée.

Derrida, Jacques (2001), "La veilleuse", en Trilling, Jacques : James Joyce ou l'écriture matricielle, París : Circe, pp. 7-33.

Derrida, Jacques (1994), "Fourmis" en Negrón, Mara (ed.): Lectures de la différence sexuelle, París : des femmes.

Derrida, Jacques (1991a), “Circonfession”, en Bennington, Geoffrey : Jacques Derrida, París : Seuil.

Derrida, Jacques (1991b), Donner le temps. 1. La fausse monnaie, París: Galilée

Kamuf, Peggy (2011), "Le veilleur”, Escritura e imagen, no. Extra 7, pp. 13-22.

Kronick, Joseph G. (2000), "Philosophy as Autobiography: The Confessions of Jacques Derrida", $M L N$, no. 115/5, pp. 997-1018.

Lisse, Michel (1999), "Le secret exemplaire de la littérature", en Zabus, Chantal (ed.) : Le secret : motif et moteur de la littérature, Louvain-la-Neuve: Université de Louvain, pp. 424-436. 
Llevadot, Laura (2015), “Hacer la verdad: El ‘yo’ de la confesión en Kierkegaard, Foucault y Derrida”, Estudios kierkegaardianos. Revista de filosofía, no. 1, pp. 149-168.

Llevadot, Laura (2010), "Para una crítica de la novela: Zambrano y Benjamin", Aurora, no. 11, pp. 77-87.

López Sáenz, María del Carmen (2007), "Los sueños, el tiempo y la pasividad. María Zambrano y la fenomenología”, La Lámpara de Diógenes, no. 8/15, pp. 59-77.

Maillard García, Ma Luisa (1996), "Mujer y narración en María Zambrano", Revista de Hispanismo Filosófico, no. 1/1, pp. 53-64.

Michaud, Ginette (2010), Comme en rêve : Volume 2. Lire Jacques Derrida et Hélène Cixous, París : Hermann.

Michaud, Ginette (2006), Tenir au secret (Derrida, Blanchot), París: Galilée.

Pérez Navarro, Pau (2001), "El sueño creador de María Zambrano. Filosofía, tiempo y tragedia", Athenea Digital, no. 0, pp. 53-64

Stevenson, Robert Louis (2013), "Ensayo sobre los sueños", en Escribir. Ensayos sobre literatura, Madrid: Páginas de Espuma, pp. 73-89.

Tarantino, Stefania (2001), "La confesión como tiempo del ser en María Zambrano y San Agustín", Aurora, no. 3, pp. 75-81.

Wittgenstein, Ludwig (2006), Luz y sombra. Una vivencia(-sueño) nocturna y un fragmento epistolar, Valencia: Pre-Textos.

Wittgenstein, Ludwig y Engelmann, Paul (2009), Cartas, encuentros, recuerdos, Valencia: Pre-Textos.

Zambrano, María (2012) [1964], “Los orígenes de la novela”, Aurora, no. 3, pp. 147-148.

Zambrano, María (2000), Hacia un saber sobre el alma, Madrid: Alianza.

Zambrano, María (1998) [1965], El sueño creador, Madrid: Universidad de Alcalá.

Zambrano, María (1994) [1965], España, sueño y verdad, Madrid: Siruela.

Zambrano, María (1995) [1943], La confesión: género literario, Madrid: Siruela.

Zambrano, María (1992), Los sueños y el tiempo, Madrid: Siruela. 